\title{
Legal Research Methodologies in European Union \& International Law: Research Notes (Part 2)
}

\section{Tamara Hervey, Rob Cryer \& Bal Sokhi-Bulley}

\author{
Project: \\ Collaborative Doctoral Training Project (ID 06/160/S) \\ Dates: \\ 1 October 2006 - 30 September 2008 \\ Project Leaders: \\ Tammy Hervey (Professor of Law, University of Sheffield) \\ Rob Cryer (Professor of Law, University of Birmingham) \\ Bal Sokhi-Bulley (PhD Candidate, University of Nottingham) \\ Funding: \\ Arts and Humanities Research Council (AHRC)
}

\section{Introduction}

This interim report reflects on this AHRC funded project at its half way point. We have developed the training materials, as discussed in our first research notes article. ${ }^{1}$ We have also held one of the two workshops.

\section{The Training Materials}

As we explained in our previous research notes article, the materials are designed to provide an accessible introduction to some of the main methodological or theoretical approaches to legal research in EU and international law. They are structured around a list of different approaches developed from our understandings of the state of the art in those two interrelated disciplines. The materials contain a brief introduction to each approach and two sample readings which either explain it or demonstrate its use - one in EU law and one in international law. We already noted some of the problems with this type of 'labelling' approach. However, we hoped that the materials would form a useful heuristic device to enhance communication between the workshop participants.

Students and staff attending the workshop were asked to read the materials in advance, and reflect on the following questions:

\footnotetext{
1 See Hervey T., Cryer, R. \& Sokhi-Bulley, B. (2007) 'Legal Research Methodologies in European Union \& International Law: Research Notes (Part 1)', Journal of Contemporary European Research, Vol. 3, No. 2, pp. 161165.
}

ISSN 1815-347X online - Hervey, T., Cryer, R. \& Sokhi-Bulley, B. (2008). 'Legal Research Methodologies in European Union \& International Law: Research Notes (Part 2)', Journal of Contemporary European Research, Vol. 4, No. 1, pp.48-51. 
- What is/are the research question(s) the author asks in this piece?

- Why should a reader or publisher be interested?

- What sources/data were used? How were they used?

- What assumptions does the author make about law and legal research?

- What type of research questions can this approach answer?

- What are the benefits and drawbacks of applying this approach?

- What would the approach and method look like, if applied to the substantive area of your PhD?

Feedback from the workshop suggests that the participants valued the materials highly, not simply as preparation for the workshop, but as useful in their later careers. While some students were somewhat daunted by the materials (we predicted this, given our experience that many law students are almost fearful of theory, because they have so little exposure to it during their undergraduate and even LLM/MA level education), most found them wellwritten and easy to follow.

\section{The Workshop}

The two-day workshop consisted of three different types of sessions: whole-group sessions; small group activities; and paper presentation panels. There were two whole group sessions: an introductory talk from the project leaders and an exercise based on Edward de Bono's 'Thinking Hats' (De Bono: 1992). This latter was the least successful part of the workshop, perhaps because it is more useful at the very beginning of a new project. The paper presentation panels - like conference panels - were the most 'traditional' part of the workshop. For the next workshop, we intend to ask students to focus more on the themes of the workshop when they prepare their presentations, and to be clear that the discussants will not be able to give feedback on the substance of the research projects.

The most innovative part of the workshop was the small group activities. These were facilitated by members of academic staff, but were very much focused on learning through a particular activity. The staff facilitators were highly praised in the workshop feedback. We used three such activities: two more serious and one more fun. The 'fun' activity was a picture quiz, involving twenty pictures, posted around the room. Teams had to identify which theory, method or approach each should be identified with, and justify their answer. There were 'prizes' for the most inventive entry and the one that made us laugh the most. We also used a 'statements debate', designed to reveal methodological tendencies (where individuals are coming from, when they choose their research projects). Participants considered twenty statements about legal research, choosing the five most important and three least important to them. In pairs, they then asked each other questions designed to encourage reflection on what the choices reveal about the methodological bases of their research projects. A 'Venn Diagram' activity involved groups taking two or three of the approaches outlined in the notes, and first jotting down any ideas, concepts, people, quotations, questions and so on associated with a particular method. They then drew a Venn Diagram representing the two approaches, and placed each idea and so on somewhere onto the Venn Diagram. This exercise was highly successful in terms of observable learning and exchange of expertise. It allowed PhD students to clarify and get feedback from the group facilitators on the main themes, ideas, and strengths or weaknesses of the various approaches to (EU and international) legal research. The exercise also demonstrated graphically the permeability of boundaries between the different approaches and the difficulties with labelling highlighted in the training materials. 
The feedback from the workshop demonstrated that the participants felt that they had increased their understandings of legal research methodologies in their discipline.

"This workshop has turned me into a theorist".

"My assumptions about theories/methodologies have changed".

"[The workshop] has made me focus on methods and theory".

Students also felt able to relate the more general methodology/theory element of the workshop to their own work. In some cases, the usefulness of this element of the workshop was unexpected.

"[The] workshop helped me refine my research questions".

"Theory is practical".

"I learned how to use theories in legal research".

"I benefited greatly from having my theoretical perspectives discussed by others".

"The theoretical discussion was more useful than I expected".

"The group exercises were more useful than I expected".

"[The workshop] was good. I started thinking about some issues which I never considered would be relevant in my thesis before".

"The discussions on methodology helped me to think more about the methodology I am using in my research".

"I would say that the workshop exceeded my expectations. I expected to gain a better overview of various approaches. I did this....and I reached some conclusions about my own approach".

"The workshop exceeded my expectations. It has been a highly didactic experience which gave me insights on my own work as well as the work of others."

"The workshop surpassed my expectations. I feel I understand myself and my thesis better".

This view was also reflected in feedback from academic staff members.

"I was hoping that this would be a relaxed forum in which students would be given a chance to chat freely about theory - including potentially why they were commonly put off by it - and in which we could all get new ideas about approaches others are using. I think the workshop was great in achieving this - I think it is easy for students to decide they want to be "doctrinal" just by fear of getting lost in theory, and this type of information forum where the idea is not to all claim that we are "theorists", but to explain if and how we try to use theory, is particularly helpful".

"I started with the impression that the project was about making a link between theory and method, and helping us to think about 'method in practice'... the workshop was very practical, introductory, innovative...".

One of the biggest challenges for the project is how to make the workshop useful for researchers at different stages of their careers. We were only partially successful in this aim. At the next workshop, we intend to be more explicit about the different constituencies present: first year $\mathrm{PhD}$ students who may still be clarifying their research questions; second/third year PhD students who are interested in how their chosen approach is working in the context of their particular project; early stage career scholars who may be considering their next big project; supervisors who may wish to develop their own research in new directions, or support students whose approaches differ from their own. But our insistence that everyone - whatever stage in their research career - can learn through reflection on theory and methodology and its practical application in real research projects was also a key 
to the workshop's successes. We worked very hard to create an atmosphere that was friendly, non-threatening and informal (as well as hard working, energetic and fun). Many of the comments on the student feedback suggested that this paid off:

"friendly";

"excellent people, the organisers";

"I ... was really pleased to find a relaxed and supportive environment";

"great - friendly, informal, energetic";

"very unusual and needed forum";

"a truly enjoyable workshop".

\section{Practical information}

The project has ten formal partner institutions (Belfast, Birmingham, Durham, Glasgow, Keele, Leicester, Liverpool, Manchester, Nottingham and Sheffield), but the project materials are freely available on the project's website ${ }^{2}$ and the workshops are open to participants from any institution. The next workshop will be held at the School of Law, University of Sheffield, on 27 and 28 June 2008. Although the project is aimed at law students, it welcomes students from all disciplines who are interested in legal research methodologies.

\section{References}

De Bono, E. (1992). Teach Your Child to How Think. London: Viking.

\footnotetext{
${ }^{2}$ The project website is available at: http://www.sheffield.ac.uk/law/research/clic/research/projects/res methodology
} 